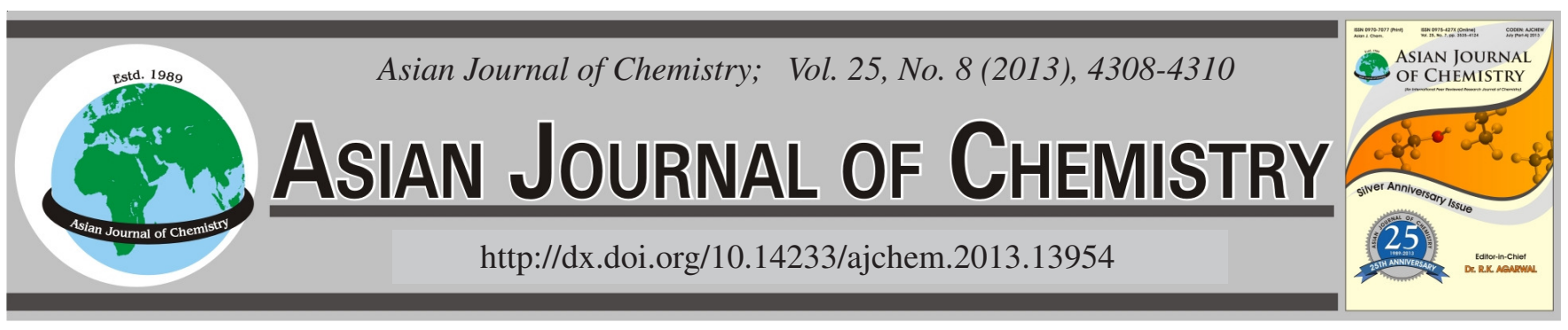

\title{
Bamboo Charcoal as Solid-Phase Extraction Adsorbent for the Simultaneous Enrichment and Sensitive Determination of Copper and Lead in Environmental Samples
}

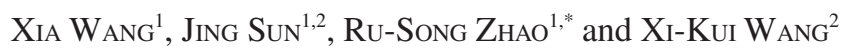 \\ ${ }^{1}$ Key Laboratory for Applied Technology of Sophisticated Analytical Instruments of Shandong Province, Analysis and Test Center, Shandong \\ Academy of Sciences, Jinan 250014, P.R. China \\ ${ }^{2}$ Shandong Institute of Light Industry, Jinan 250353, P.R. China \\ *Corresponding author: E-mail: zhaors1976@126.com \\ (Received: 24 April 2012; \\ Accepted: 9 February 2013) \\ AJC-12951

\begin{abstract}
In this paper, the potential of bamboo charcoal as solid-phase extraction (SPE) adsorbent for the enrichment and determination of heavy metals at trace level in environmental water samples has been investigated. $\mathrm{Cu}^{2+}$ and $\mathrm{Pb}^{2+}$ were selected as the model analytes and inductively coupled plasma atomic emission spectrometry (ICP-AES) for the detection. Important factors affecting enrichment efficiencies environmental samples with satisfactory results.

Key Words: Bamboo charcoal, Copper, Lead, ICP-AES, Water samples.
\end{abstract} \\ of the analytes, such as sample $\mathrm{pH}$, elution concentration and its volume, flow rate of sample, sample volume and interfering ions, have \\ been investigated. The proposed method has been successfully applied for the enrichment and determination of trace heavy metals in
}

\section{INTRODUCTION}

Among sample pretreatment methods, solid-phase extraction (SPE) is the most frequently-used one for the pretreatment of environmental water samples because of its many advantages such as high recovery, high enrichment factors, low consumption of solvents, simplicity, easy automation and simple operation. In order to achieve higher enrichment efficiencies for trace metal ions, the choice of suitable adsorbents for solidphase extraction is very important. Various new types of hydrophobic materials, such as carbon nanotubes, functionalized magnetite microspheres, chelating resin, have been used as adsorbents for the enrichment and determination of metal ions and favorable results were obtained ${ }^{1,2}$. For solid-phase extraction, novel adsorbents with inexpensive, highly selective and lifelong properties are still urgently needed.

Bamboo charcoal has attracted great attention because of its unique microporous structure and biological characteristics. The porosity of bamboo charcoal is about five times more and the absorption efficiency is ten times higher than that of wood charcoal $^{3}$. In terms of specific surface area, bamboo charcoal $\left(300 \mathrm{~m}^{2} \mathrm{~g}^{-1}\right)$ is ten times greater than wood carbon $\left(30 \mathrm{~m}^{2} \mathrm{~g}^{-1}\right)$. In addition, bamboo charcoal is a kind of low cost material, which is much lower than other adsorbents such as polymer, carbon nanotubes, etc. The low price, large surface area and excellent stability make bamboo charcoal a promising adsorbent material for the routine analysis of environmental pollutants. It has been successfully used as solid-phase extraction adsorbent for the enrichment and determination of organic pollutants s.5 $^{4,5}$ in environmental water samples and satisfactory results were obtained. It is novel and effective to use bamboo charcoal as solid-phase extraction adsorbent for the determination of copper and lead at trace level in real water samples.

In this paper, the potential of bamboo charcoal as solidphase extraction adsorbent for the enrichment and determination of heavy metals at trace level in environmental samples has been investigated. $\mathrm{Cu}^{2+}$ and $\mathrm{Pb}^{2+}$ were selected as the model analytes and ICP-AES for the detection. Related factors affecting the enrichment of the analytes, such as sample $\mathrm{pH}$, flow rate of sample, sample volume, elution solution and its volume and interfering ions, have been studied and optimzied in detail. Then the proposed method was applied for the analysis of trace heavy metals in real-world environmental samples.

\section{EXPERIMENTAL}

IRIS Advantage inductively coupled plasma atomic emission spectrometer (Thermo Elemental, MA, USA) was used. $\mathrm{HNO}_{3}$ was of guaranteed reagent (Sinopharm Chemical Reagent Co., Ltd., China). Stock solutions of copper and lead at $1000 \mathrm{mg} \mathrm{L}^{-1}$ were prepared with high purified metal copper and lead (National Research Center for Certified Reference Material, Beijing, China, > $99.99 \%$ ), respectively. Working 
solutions were obtained by further diluting the stock solution before use. All the other reagents and chemicals were of analytical grade unless otherwise stated.

The physical characterization of bamboo charcoal and preparation of bamboo charcoal based-solid-phase extraction cartridges have been reported in the previous researches ${ }^{4,5}$. The solid-phase extraction cartridge was pretreated by washing with $3 \mathrm{~mL} 1.0 \mathrm{~mol} \mathrm{~L}^{-1} \mathrm{HNO}_{3}$ and $5 \mathrm{~mL}$ purified water prior to each solid-phase extraction procedure. Then $100 \mathrm{~mL}$ water sample was passed through the pre-conditioned cartridge at the optimum flow rate. After sample solution had passed through, the cartridge was washed with $5 \mathrm{~mL}$ purified water to clean impurity. Afterwards, each cartridge was dried by applying negative pressure for 10 min with the vacuum pump. Then $3 \mathrm{~mL} 1.0 \mathrm{~mol} \mathrm{~L}^{-1} \mathrm{HNO}_{3}$ was used to elute the analytes retained on the cartridge. Finally, $\mathrm{Cu}^{2+}$ and $\mathrm{Pb}^{2+}$ in the eluant were analyzed by ICP-AES.

\section{RESULTS AND DISCUSSION}

In order to evaluate the enrichment potential of bamboo charcoal, the parameters affecting the enrichment efficiencies of $\mathrm{Cu}^{2+}$ and $\mathrm{Pb}^{2+}$, such as sample $\mathrm{pH}$, eluant concentration and volume, flow rate of sample, sample volume and interfering ions, were investigated and optimized.

The $\mathrm{pH}$ of sample solution is an important factor affecting the enrichment efficiencies of metal ions on the bamboo charcoal. To examine the influence of sample $\mathrm{pH}$ on the recoveries of $\mathrm{Cu}^{2+}$ and $\mathrm{Pb}^{2+}$, a series of experiments were performed by changing the $\mathrm{pH}$ from 2 to 10 . The experimental results show that the two metal ions were adsorbed much better at $\mathrm{pH}$ 7-9 and the recoveries could exceed $90 \%$ at $\mathrm{pH} 8$. According to the above experimental results, sample $\mathrm{pH}$ was adjusted to 8 in the following experiments.

It is essential to select a proper eluant for the desorption of target analytes from the solid-phase extraction column. It is obvious that the enrichment efficiencies of the two ions can be negligible at $\mathrm{pH}<2$, which indicated that strong acid condition could be effective to elute heavy metal ions from the solid-phase extraction cartridge. Therefore, conc. $\mathrm{HNO}_{3}$, was selected to eluate both of $\mathrm{Cu}^{2+}$ and $\mathrm{Pb}^{2+}$ from the solidphase extraction column. $0.5,1.0$ and $2.0 \mathrm{~mol} \mathrm{~L}^{-1} \mathrm{HNO}_{3}$ were investigated for the desorption of $\mathrm{Cu}^{2+}$ and $\mathrm{Pb}^{2+}$ from bamboo charcoal column, respectively. $1 \mathrm{~mol} \mathrm{~L}^{-1} \mathrm{HNO}_{3}$ achieved higher quantitative recoveries for $\mathrm{Cu}^{2+}$ and $\mathrm{Pb}^{2+}$ than other concentrations. Therefore, $1 \mathrm{~mol} \mathrm{~L}^{-1} \mathrm{HNO}_{3}$ was adopted in the following experiments.

Then the influence of eluant volume on the recoveries of $\mathrm{Cu}^{2+}$ and $\mathrm{Pb}^{2+}$ was investigated. A series of experiments were designed and performed by changing the volume of $1 \mathrm{~mol} \mathrm{~L}^{-1}$ $\mathrm{HNO}_{3}$ over the range 3-7 mL. The experimental results indicated that all the volumes in the range of 3-7 mL could obtain the quantitative recoveries (>90\%). The lowest volume that instrumental determination needed was $3 \mathrm{~mL}$. Therefore, we chose the lowest volume $3 \mathrm{~mL} 1.0 \mathrm{~mol} \mathrm{~L}^{-1} \mathrm{HNO}_{3}$ as the eluant in all subsequent experiments.

The flow rate of the sample affects the recoveries of target analytes and controls the sample loading time. Here the flow rate of the sample was optimized over the range of $0.8-2 \mathrm{~mL}$ $\min ^{-1}$ with the limitation on the negative pressure of the pump.
In this experiment, the flow rate had no obvious influence on their extraction efficiencies. The recoveries of $\mathrm{Cu}^{2+}$ and $\mathrm{Pb}^{2+}$ were found between 88.0-93.2\%. To save extraction time, the

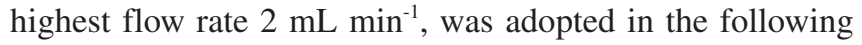
experiments.

A series of experiments were designed and performed to obtain higher enrichment factor by changing sample volume. The sample volume was investigated over the range of 50-250 $\mathrm{mL}$. The experimental results indicated that all of the quantitative recoveries were above $90 \%$ for $\mathrm{Cu}^{2+}$ and $\mathrm{Pb}^{2+}$. When the volume reached to $100 \mathrm{~mL}$, the highest recoveries could be obtained for the both metal ions. In order to save sample pretreatment time, $100 \mathrm{~mL}$ of sample volume was adapted in the subsequent experiments.

The stability and regeneration potential of the cartridge packed with bamboo charcoal were investigated. The solidphase extraction column can be regenerated with $3 \mathrm{~mL} 1 \mathrm{~mol}$ $\mathrm{L}^{-1} \mathrm{HNO}_{3}$ and $5 \mathrm{~mL}$ purified water prior to each reuse and still stable more than 50 adsorption-eluation cycles of the standard solutions without obvious decrease in the recoveries of the two ions.

In environmental water samples, many coexisting ions influenced the enrichment efficiencies of the two metal ions by competitive adsorption. In order to evaluate the influence of coexisting ions, main cations and anions with different levels in $50 \mathrm{ng} \mathrm{mL} \mathrm{Lu}^{-1} \mathrm{Cu}^{2+}$ and $\mathrm{Pb}^{2+}$ working solutions, passed through the solid-phase extraction column. The experimental results showed that the recoveries of the two metal ions were obtained in the range of 84.5-105.8\% under the inference of main coexisting ions. It can be concluded that the existence of the coexisting ions at relatively high levels had no obvious influence on the recoveries of $\mathrm{Cu}^{2+}$ and $\mathrm{Pb}^{2+}$ under the optimum conditions.

Under the above optimum conditions, important characteristics of the proposed method were investigated to evaluate its stability and sensitivity. Linear ranges were 0.5-500 and $1-500 \mathrm{ng} \mathrm{mL}^{-1}$ and correlation coefficients $(\mathrm{n}=6)$ were 0.9994 and 0.9996 for $\mathrm{Cu}^{2+}$ and $\mathrm{Pb}^{2+}$, respectively. The LODs, based on a signal-to-noise ratio $(\mathrm{S} / \mathrm{N})$ of 3 , were 0.15 and $0.3 \mathrm{ng} \mathrm{mL}^{-1}$ for $\mathrm{Cu}^{2+}$ and $\mathrm{Pb}^{2+}$, respectively. To assess the precision of the measurement, the repeatability of the proposed method was determined by performing six times using aqueous standard solutions with $10 \mathrm{ng} \mathrm{mL}{ }^{-1} \mathrm{Cu}^{2+}$ and $\mathrm{Pb}^{2+}$. The RSDs were 3.1 and $3.7 \%$ for $\mathrm{Cu}^{2+}$ and $\mathrm{Pb}^{2+}$, respectively, which demonstrated that the proposed method could be good repeatability.

In order to demonstrate the feasibility of the proposed method, it was then applied to determine the concentration of copper and lead in a geochemical standard reference sample (GBW-07406). $0.1 \mathrm{~g}$ reference sample was transferred into crucible. After $3 \mathrm{~mL}$ of conc. $\mathrm{HNO}_{3}, 3 \mathrm{~mL}$ of $\mathrm{HF}$ and $2 \mathrm{~mL}$ of $\mathrm{HClO}_{4}$ were added, the solution was heated to be transparent and continuously heated until near dryness. All the procedures were deducted by the blank. The residue dissolved in purified water up to $100 \mathrm{~mL}$ and the $\mathrm{pH}$ of the solution was adjusted to 8.0. The amount of $\mathrm{Cu}^{2+}$ and $\mathrm{Pb}^{2+}$ was investigated following the solid-phase extraction procedure under the above optimum conditions. From experimental results shown in Table-1, it can be seen that the results obtained were in good agreement with the reference values. 


\begin{tabular}{ccc}
\hline \multicolumn{2}{c}{ TABLE-1 } \\
& \multicolumn{2}{c}{$\begin{array}{c}\text { ANALYTICAL RESULTS OF GEOCHEMICAL } \\
\text { STANDARD REFERENCE SAMPLE }\end{array}$} \\
\hline Element & Found $^{\text {a }}\left(\mathrm{mg} \mathrm{kg}^{-1}\right)$ & Reference value $\left(\mathrm{mg} \mathrm{kg}^{-1}\right)$ \\
\hline $\mathrm{Cu}$ & $396 \pm 2$ & $390 \pm 14$ \\
$\mathrm{~Pb}$ & $314 \pm 10$ & $314 \pm 13$ \\
\hline${ }^{a} \mathrm{The}$ value following “ \pm ” is the standard deviation $(\mathrm{n}=4)$.
\end{tabular}

\section{Conclusion}

The adsorption potential of metal ions on bamboo charcoal has been investigated systematically and a simple, rapid and reliable method has been developed for the enrichment and determination of metal ions in environmental samples based on using bamboo charcoal as solid-phase extraction adsorbents. The solid-phase extraction column could be reused at least 50 times without obvious decrease in the recoveries of the metal ions. Meantime, it did not need any complicated pretreatment procedure. More important, from the economic point of view, bamboo charcoal is much cheaper than other adsorbents, which is most suitable for the routine analysis of heavy metals in large numbers of environmental samples. In summary, bamboo charcoal exhibited excellent potential for the enrichment and determination of metal ions in aqueous samples and would have a wide application perspective in the future.

\section{ACKNOWLEDGEMENTS}

This work was financially supported by the National Natural Science Foundation of China (21007035), Natural Science Foundation of Shandong Province (ZR2010BL029, Y2008B66) and Basic Foundation of Shandong Academy of Sciences (201047).

\section{REFERENCES}

1. Y.-F. Huang, Y. Li, Y. Jiang and X.-P. Yan, J. Anal. At. Spectrom., 25, 1467 (2010).

2. X.X. Zhang, M.L. Chen, Y.L. Yu, T. Yang and J.H. Wang, Anal. Methods, 3, 457 (2011)

3. L. Hua, W.X. Wu and Y.X. Liu, Environ. Sci. Pollut. Res. 16, 1 (2009).

4. R.-S. Zhao, X. Wang, J.-P. Yuan and J.-M. Lin, J. Chromatogr. A, 1183, 15 (2008).

5. R.-S. Zhao, C. Hu, J.-B. Zhou, J.-P. Yuan, S.-S. Wang and X. Wang, Anal. Bioanal. Chem., 400, 118 (2011). 